\title{
OBSERVATIONS ON THE TEMPERATURE REGULATION AND WATER ECONOMY OF THE GALAH (CACATUA ROSEICAPILLA)
}

\author{
William R. Dawson and Charles D. Fisher* \\ Division of Biological Sciences and Museum of Zoology. The University of Michigan, \\ Ann Arbor, Michigan 48109, U.S.A.
}

(Received $30 \mathrm{Jul}$, 1981)

\begin{abstract}
Galahs (Cacatua roseicapilla), like many other birds, undergo controlled hyperthermia in hot environments.

2. Basal metabolism of galahs $(271 \mathrm{~g})$ at night during summer averages $0.93 \mathrm{~cm}^{3} \mathrm{O}_{2}(\mathrm{~g} \cdot \mathrm{hr})^{-1}$ vs 0.90 predicted.

3. They can evaporatjvely dissipate heat at 1.4-1.7 times the rate of metabolic heat production at high ambient temperatures $\left(T_{A}\right)$.

4. Under moderate $T_{4}$ and humidity, galahs must minimally drink $7,3 \mathrm{~g} \mathrm{H}_{2} \mathrm{O} / 24 \mathrm{hr}$. Without water they lose $2.2^{\circ}{ }_{0}$ body mass $24 \mathrm{hr}$. Some of these birds benefited from drinking $0.3 \mathrm{M} \mathrm{NaCl}$.

5. Galahs occupy arid Australia through good powers of heat defense, some resistance to dehydrating conditions, and mobility allowing them to reach both water and food.
\end{abstract}

\section{INTRODUCTION}

Parrots and thcir allies represent a major element in the avifauna of arid portions of Australia. Among these birds none is more conspicuous and widespread than the galah (Cacatua roseicapilla). This small cockatoo uses its strong powers of flight to forage widely and to return periodically to watering points which it uses extensively, particularly in hot weather (Fisher et al., 1972). It has been the subject of some studies concerning mechanisms governing cloacal water loss and renal performance (Skadhauge, 1974a,b; Johnson \& Skadhauge, 1975; Skadhauge \& Dawson. 1980). We report here observations on its energy metabolism, temperature regulation, and water economy, which we feel are pertinent to an understanding of the nature of the adjustments of the galah to a demanding environment.

\section{MATERIALS AND METHODS}

\section{Experimental subjects}

The galah is widely distributed across the arid interior of Australia and has expanded its range into adjacent agricultural areas in recent times. The majority of the birds of this species used in the laboratory portion of our study were obtained by gift or purchase in Perth. Western Australia. and are subsequently referred to as "WA" galahs. They were maintained at the University of Western Australia, Nedlands, in outdoor aviaries measuring $1.2 \times 2.0 \times$ $5.2 \mathrm{~m}$. Some shade and shelter from rain and the night sky were available in these structures. Water and food consistIng of sunflower, millet, thistle. and milo maize seeds were provided ad lib. Four other galahs that had been obtained from a bird dealer in Sydney, New South Wales. hereafter

* Present address: Department of Biology, Stephen F Austin University. Nacogdoches. TX 75961. U.S.A. referred to as "NSW" birds, were studied at the University of New South Wales, Kensington. These birds were maintained in a $1.5 \times 0.7 \times 0.7 \mathrm{~m}$ cage in an unheated animal house.

\section{Temperature measurements}

Temperatures in metabolism chambers $(T)$ were measured with 30 -ga. copper-constantan thermocouples used in conjunction with a Honeywell recording potentiometer. Thermocouples of this type encased in fine polyethylene catheter tubing, or Schultheis thermometers were used for registration of cloacal temperatures, $T_{\mathrm{cl}}(2 \mathrm{~cm}$ insertion), when a galah was removed from a metabolism chamber at the end of a metabolic test. A few measurements of $T_{\mathrm{c}}$ were obtained in the field using a Schultheis thermometer on birds that had just been shot. Some measurements of body temperature $\left(T_{\mathrm{b}}\right)$ were also made by telemetry using a $1 \times 1.5 \times 3-\mathrm{cm}$ temperature transmitter (Sensory Systems, Inc.) implanted in the abdominal cavity. This device contained a blocking oscillator circuit and temperature was determined from pulse frequency. Transmission range was sufficient to allow measurements to be made with the observer concealed from the bird. Implantations were done on galahs anesthetized with Equithesin. A three-day period was allowed for recovery before any measurements were attempted.

\section{Metabolism and etaporatice water loss}

In tests at $T$ above $20 \mathrm{C}$, which were all carried out on WA birds during January and early February (austral summer), standard metabolism and evaporative water loss were measured simultaneously at approximately $2200 \mathrm{hr}$, using post-absorptive galahs. These birds, which were tested singly, had been resting in the dark for $6-8 \mathrm{hr}$ in a metal chamber housed in a thermostatically controlled room or constant temperature cabinet. The details of the open circuit metabolism system of which the 18.2-liter chamber was a part are described by Dawson and Fisher (1969) Metabolism was measured as oxygen consumption $\left(\dot{V} \mathrm{O}_{2}\right)$. using paramagnetic oxygen analysis. Evaporative water loss ( $\left.\dot{m}_{w}\right)$ was determined gravimetrically, the gains in mass of drying tubes containing Drierite lanhydrous 


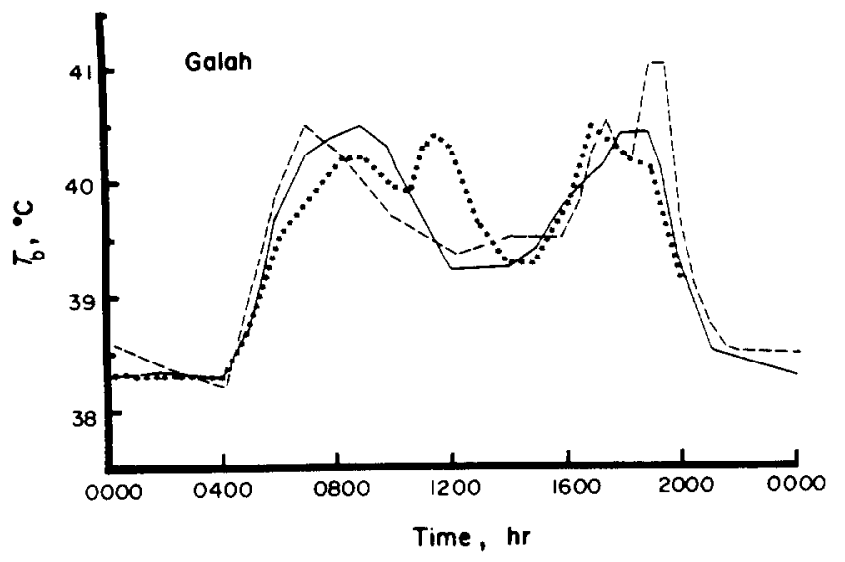

Fig. 1. Body temperature $\left(T_{\mathrm{b}}\right)$ obtained by telemetry from a galah with a temperature transmitter implanted in the body cavity. Records pertain to the period of 8-15 February, when sunrise and sunset occurred at approximately 0550 and $1900 \mathrm{hr}$, respectively. Ambient temperatures on the three days illustrated range from a low of $19-21 \mathrm{C}$ at night to $30-35 \mathrm{C}$ during the day. Daytime $T_{\mathrm{b}}$ appeared uncorrelated with maximum $T_{\star}$.

$\mathrm{CaSO}_{4}$ ) being measured on a Mettler balance of appropriate sensitivity. A galah rested in the chamber on a platform of wire mesh over a $2-\mathrm{cm}$ pool of mineral oil, which received any droppings voided during tests. This prevented them from adding water vapor to the air flowing through the system. which had been dried initially by passing through a Drierite train. Rates of air flow varied from 850 to $6840 \mathrm{~cm}^{3} / \mathrm{min}$ among the various tests. higher rates being used at warmer $T_{x}$. This made it possible to maintain chamber humidity at 12-16 torr in tests at $T_{d}$ of $40-47.5 \mathrm{C}$. Measurements verified that the drying trains used for determination of evaporative water loss absorbed more than $99^{\circ}$ of known amounts of water vapor introduced into the metabolism system, even at the highest rates of air flow used in actual tests. Prior to tests, absorption of water vapor at the relevant flow rate was measured without an animal in the chamber to determine the correction. if any, needed subsequently in apparent $\dot{m}_{\text {we }}$.

A few additional measurements of $\dot{\mathrm{VO}} \mathrm{O}_{2}$ were carried out near $O C^{\prime}$ in August (austral winter) on the four NSW galahs. which were being maintained at $T_{\perp}$ of $11-19 \mathrm{C}$. These measurements involved use of a metabolism system of the same basic design as that used in Western Australia. However, it employed a 13.2-liter lucite chamber rather than the larger one described previously, and rates of air flow. which were set at constant levels between 2000 and $3000 \mathrm{~cm}^{3} \mathrm{hr}$, were measured with a gas meter rather than a rotameter. Procedures. timing and duration for tests were similar to those described previously.

\section{Water bulance studies}

Observations concerning water economy of WA galahs were made on birds confined individually in $60 \times 60 \times 60+\mathrm{cm}$ cages housed in a constant temperature room during the months of April-August (austral fall and winter). Photoperiod and $T_{\downarrow}$ were maintained at $12 \mathrm{hr}$ day and $20-22^{\circ} \mathrm{C}$. Humidity in the constant temperature room varied between 55 and $70^{\circ}$ RH (ca 10 and 13 torr), based on determinations with a sling psychrometer. Galahs frequently lost or gained a few grams when transferred from the outdoor aviary to the constant temperature room. Consequently. observations on water balance were not begun until body mass had restabilized. This period of $7-10$ days allowed the animals to adjust to their new. more confined surroundings and to learn to use the watering devices (plastic drinking cup holding inverted glass reservoir attached to side of cage) with which fluid consumption was measured. Food was available ad lih. in the cages. In tests. measurements were made of body mass, water consumption. food intake. and moisture content and dry mass of excrement produced. All of these were determined using an Ohaus triple beam, Mettler top loading, or Mettler analytical balance. depending on the sensitivity required. Determination of water consumption included a correction for evaporation based on the amount of water lost over the course of a test from a watering device placed near the cages but out of reach of any of the birds. Several droppings were collected daily on aluminum foil during tests. These were collected and weighed immediately and then dried at $105 \mathrm{C}$. Moisture content of the excrement was determined as the difference between the collection and post drying masses. The remaining excrement was also collected daily. dried at $105 \mathrm{C}$. and weighed to determine the dry mass of the material voided daily.

Ad libitum consumption of water by galahs was measured and the daily water ration then reduced by small amounts until the birds started to lose body mass. The lowest daily fluid intake sufficient to maintain body mass was taken as approximating the minimal adequate water consumption. The course of body mass of birds provided with $0.3 \mathrm{M} \mathrm{NaCl}$ as their only fluid source or deprived of drinking water entirely was also followed, intake of the $\mathrm{NaCl}$ solution being measured gravimetrically, with a correction for evaporation.

Under the humidity conditions in the constant temperature room used in these studies, the moisture content of the seeds provided the birds ranged from 9.1 to $12.2^{\circ}{ }_{0}$. as determined by drying for $24 \mathrm{hr}$ at $105 \mathrm{C}$.

In the ensuing portions of this report various mean values are given with their standard errors.

\section{RESULTS}

\section{Body temperature}

A WA galah fitted with the temperature transmitter was maintained undisturbed during early February at $T_{\lrcorner}$of $19-35^{\circ} \mathrm{C}$ and a natural photoperiod to determine the extent of any diurnal temperature cycle. Body temperature of this bird varicd from 38.2 to $41^{-} \mathrm{C}$ (Fig. 1). Morning and late afternoon peaks of $T_{\mathrm{b}}$ are apparent, perhaps associated with the main bouts of feeding for the day. From midmorning $(1000 \mathrm{hr})$ through late afternoon $(1600 \mathrm{hr}), T_{\mathrm{b}}$ approximated 


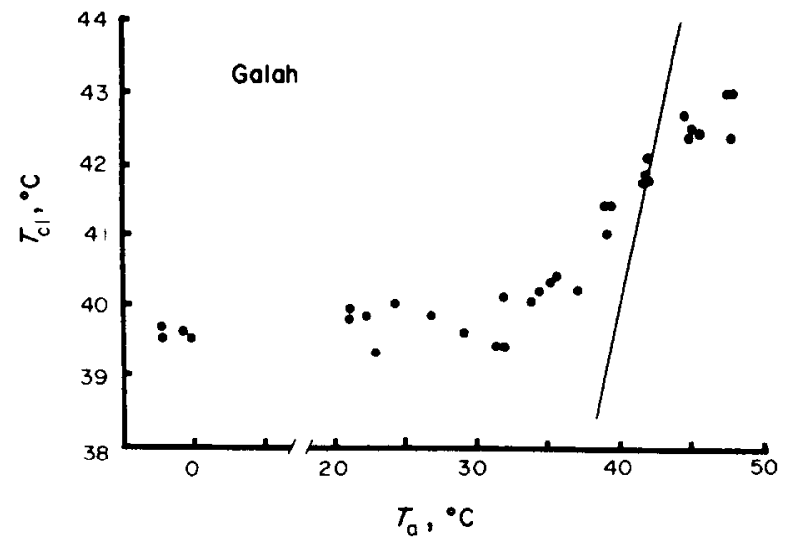

Fig. 2. Relation of body temperature $\left(T_{b}\right)$ determined at the end of metabolic tests to ambient temperature $\left(T_{4}\right)$. The values for $T_{4}>20 \mathrm{C}$ are for Western Australian birds in summer. Those for $T_{a}$ near $0 \mathrm{C}$ are for New South Wales galahs in winter.

$40 \mathrm{C}$. only $0.8 \mathrm{C}$ above the general night-time level. Suggestions of a similar temperature cycle exist in our observations on galahs in nature. On Thundelarra Station. Western Australia, $T_{\mathrm{b}}$ of individuals collected at $0830 \mathrm{hr}$ averaged about $40.5 \mathrm{C}$. Some galahs had $T_{\mathrm{b}}$ as low as $39.5^{\circ} \mathrm{C}$ at $1330 \mathrm{hr}$. At $1830 \mathrm{hr}$, just before sunset, the birds averaged about $41.5^{\circ} \mathrm{C}$.

Temperatures of WA and NSW galahs at the end of metabolic tests appear independent of $T_{4}$ between approximately 0 and $33 \mathrm{C}$ (Fig. 2). Above the latter temperature, $T_{\mathrm{cl}}$ tended to rise with increasing external temperature, though the rate of increase slowed somewhat above approximately $40 \mathrm{C}$. At $T_{4}$ above $42 \mathrm{C}$, the animals remained cooler than their surroundings for up to several hours at ambient temperatures as high as $47^{\circ}-48^{\circ} \mathrm{C}$. Two birds tested at this upper limit became heated to only $43 \mathrm{C}$. The thermoregulatory capacity of this species at high $T_{d}$ is lllustrated further in Fig. 3, which records the course of $T_{\mathrm{b}}$ obtained by telemetry during exposure of a WA bird to $48 \mathrm{C}$ for $5 \mathrm{hr}$. Body temperature at the completion of this test was $44.2 \mathrm{C}$. Prolonged exposure of galahs to $48-50 \mathrm{C}$ in metabolic tests did lead to overheating. One animal had a $T_{\mathrm{h}}$ of $45.8 \mathrm{C}$ at the conclusion of such a test and died shortly afterward.

\section{Stundard metabolism}

Values of standard metabolism for WA birds in summer, measured as $\dot{V} \mathrm{O}_{2}$ at $T_{1}$ of 21 to $48 \mathrm{C}$, are plotted in Fig. 4. The zone of thermal neutrality is not sharply defined by these data, but it appears to extend from approximately $22.5^{\circ}$ to $33 \mathrm{C}$. One to four values of $\dot{V O}_{2}$ were obtained in this interval for each of 11 birds in this group (mean body mass $271.0 \pm 8.28 \mathrm{~g}$ ). The lowest of these values was taken as the basal metabolic rate (BMR) of the particular individual. The mean of these minimal values for the 11 birds is $0.93 \pm 0.025 \mathrm{~cm}^{3} \mathrm{O}_{2}(\mathrm{~g} \cdot \mathrm{hr})^{-1}$. Galahs engaged in vigorous panting movements (see below) at high $T$ and this led to metabolic rates nearly twice BMR at $48 \mathrm{C}$.

Some indication of responses of galahs to low temperatures is provided by observations on the four NSW birds in winter. These were heavier than their

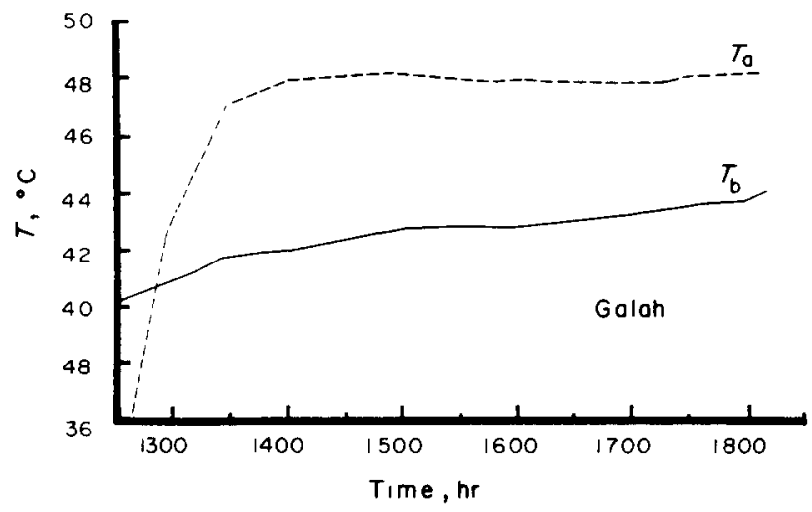

Fig. 3. Body temperature $\left(T_{\mathrm{b}}\right)$ obtained by telemetry from a galah with a temperature transmitter implanted in the body cavity. (This is the same individual to which the data presented in Fig. 1 pertain). The ambient temperatures $\left(T_{4}\right)$ to which the bird was exposed over approximately $5 \mathrm{hr}$ are also plotted. While at $T_{4}$ of $47.9^{\circ} \mathrm{C}-48.1^{\circ} \mathrm{C}$, this galah evaporated water at the following rates: $5.7 \mathrm{~g} / \mathrm{hr}(1400-1415 \mathrm{hr})$. $6.1 \mathrm{~g} / \mathrm{hr}(1500-1515 \mathrm{hr}), 5.8 \mathrm{~g} / \mathrm{hr}(1600-1615 \mathrm{hr}), 5.7 \mathrm{~g} / \mathrm{hr}(1700-1715 \mathrm{hr}) 6.1 \mathrm{~g} / \mathrm{hr}(1800-1815 \mathrm{hr})$. At the beginning of the test it weighted $284.5 \mathrm{~g}$. It had declined to $248.5 \mathrm{~g}$ by the end. a loss of body mass equivalent to $13^{\circ}$ of the initual value. 


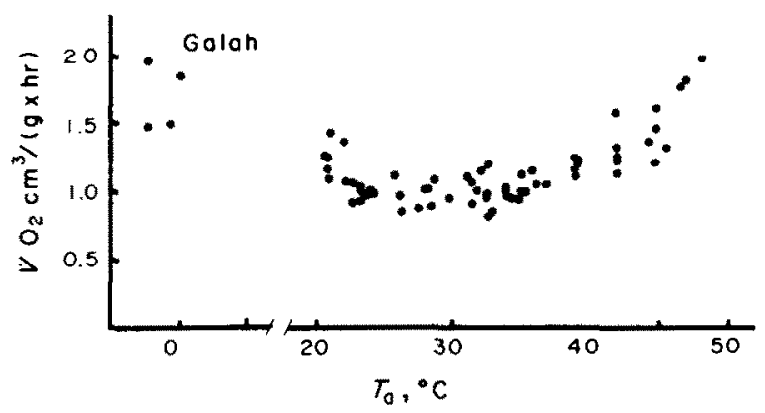

Fig. 4. Relation of nocturnal metabolic rate $\left(\mathrm{VO}_{2}\right)$ to ambient temperature $\left(T_{d}\right)$ for postabsorptive galahs resting in the dark. Values for $T_{x}>20 \mathrm{C}$ are for Western Australian birds in summer. Values for $T_{1}$ near $0 \mathrm{C}$ are for New South Wales birds in winter.

WA counterparts (average body masses 321 and $271 \mathrm{~g}$. respectively). At temperatures of -0.1 to $-2.4 \mathrm{C}$, these NSW galahs had metabolic rates averaging $1.7 \mathrm{~cm}^{3} \mathrm{O}_{2}(\mathrm{~g} \cdot \mathrm{hr})^{-1}$. This is 1.8 times the BMR observed for their smaller western counterparts in summer.

\section{Eraporative water loss}

Evaporative water loss under standard conditions increased nearly 40 -fold between 20.8 and $48.0 \mathrm{C}$ in the WA galahs studied in summer. On a semilogarithmic grid (Fig. 5), $\dot{m}_{u v}$ bears a complex relation to $T_{u}$. increasing at a substantially higher rate at $T_{4}$ above $33 \mathrm{C}$ than below. As noted previously, $33 \mathrm{C}$ approximates the upper boundary of the zone of thermal neutrality. Most interspecific comparisons of rates of evaporative water loss by birds have been carried out at $25 \mathrm{C}$ (see Discussion). A straight line free-hand fitted to the points for $T_{a}$ of $20.8-33 \mathrm{C}$ in Fig. 5 gives a rate of $0.92 \mathrm{mg}(\mathrm{g} \cdot \mathrm{hr})^{-1}$ at this temperature.

WA galahs increased respiratory evaporation in hot environments by panting. which entailed vigorous thoracic movements. A full scale response to heat stress also included noticeable pumping movements of the fleshy tongue. These movements appeared coincident with the breathing movements. The tongue

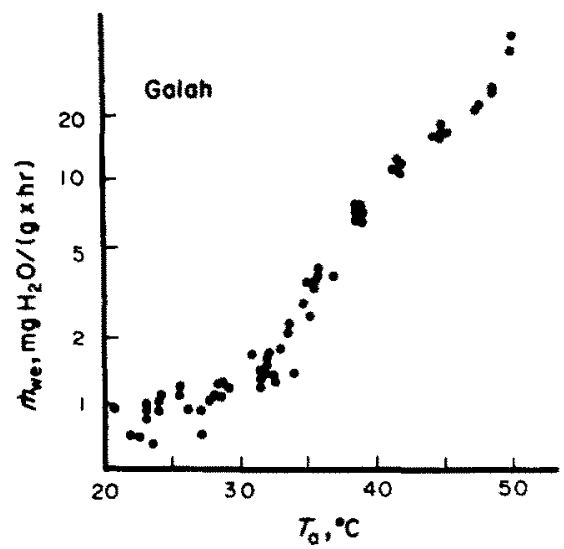

Fig. 5. Relation of evaporative water loss $\left(\dot{m}_{* \psi}\right)$ to ambient temperature $\left(T_{s}\right)$ plotted on a semilogarithmic grid. Chamber humidities were maintained below 16 torr in all tests. The values shown were obtained simultaneously with those for $\dot{V} \mathrm{O}_{2}$ (see Fig. 4). movements seemed to foster movements of the gular area. which likewise coincided with breathing. Like other birds under heat stress. galahs held their wings out from the body, thereby exposing the thinly feathered sides of the thorax. When the temperature gradient is in the proper direction, such a response presumably facilitates convective heat loss.

Galahs expended substantial amounts of water in evaporative cooling at high $T_{\mathrm{x}}$. The WA individual maintained at $48 \mathrm{C}$ for nearly $5 \mathrm{hr}$ sustained rates of evaporation fluctuating between 5.7 and $6.1 \mathrm{~g} \mathrm{H}_{2} \mathrm{O} \mathrm{hr}$ (Fig. 3). Total evaporative loss over the period was estimated from five determinations of $\dot{m}_{w c}$ to approach $29.4 \mathrm{~g}$. This represents $10^{\circ}$ of original body mass (284.5 g) of the particular bird and perhaps $15^{\circ}{ }_{0}$ of initial total body water. The bird appeared very weak upon removal from the metabolism chamber. Eighteen hours later it had restored more than $80^{\circ}{ }_{\circ}^{\circ}$ of the mass loss during the bout of heat stress. The deficit had been completely eliminated a day later.

Ad libitum water consumption and minimal water requirements at moderate $\mathrm{T}_{a}$

Ad libitum drinking of water by 278 -g WA galahs at $20-22 \mathrm{C}$ and $10-13$ tor humidity averaged $11.3 \pm 0.54 \mathrm{~g} 24 \mathrm{hr}$. or $4.0 \pm 0.15^{\circ}{ }^{\circ}$ of body mass $24 \mathrm{hr}$. $(n=11)$. Mean rates of food intake and excrement production at this rate of fluid consumption were $9.0 \pm 1.00 \mathrm{~g} 24 \mathrm{hr}$ and $2.2 \pm 0.22 \mathrm{~g}$ (dry mass) $24 \mathrm{hr}$. respectively. The former rate is far below the $24 \mathrm{~g} / 24 \mathrm{hr}$ reported for $267 \mathrm{~g}$ WA galahs (Skadhauge, 1974a) and the latter is over twice the $0.9 \mathrm{~g}$ 24 hr obtained for $300-\mathrm{g}$ NSW individuals (Skadhauge \& Dawson. 1980). Moisture content of the excrement averaged $75.4 \pm 0.67^{\circ}{ }_{0}(n=11)$, which is somewhat lower than the $82.5 \pm 1.3^{\circ}$ oreported by Skadhauge \& Dawson (1980). Although our galahs had an assortm ment of seeds available, they ate sunflower seed kernals (Helianthus) almost exclusively.

In 20 instances involving $5 \mathrm{WA}$ galahs. consumption of an average of $7,3 \mathrm{~g}$ of $\mathrm{H}_{2} \mathrm{O} / 24 \mathrm{hr}$ (equivalent to $2.6^{\circ}{ }_{0}$ of body mass $24 \mathrm{hr}$ ) permitted maintenance of a stable body mass. The birds lost mass at a rate of $1-2 \mathrm{~g} 24 \mathrm{hr}$ when the water ration was reduced to $6.5 \mathrm{~g} / 24 \mathrm{hr}\left(2.3^{\circ}\right.$ of body mass, $\left.24 \mathrm{hr}\right)$. The higher figure for water intake is used here as the minimum daily ration for the galah under the particular conditions: $T_{d}, 20-22 \mathrm{C}$ : humidity, $10-13$ torr: water con- 
tent of diet, ca $11^{\circ}{ }_{0}$. However, the true figure actually lies somewhere between this value and $6.5 \mathrm{~g}$ $\mathrm{H}_{2} \mathrm{O} / 24 \mathrm{hr}$. A drinking rate of $7.3 \mathrm{~g} \mathrm{H}_{2} \mathrm{O} / 24 \mathrm{hr}$ was accompanied by a food intake of $8.9 \pm 1.32 \mathrm{~g} / 24 \mathrm{hr}$ (metabolizable energy value, ca $50 \mathrm{kcal} / 24 \mathrm{hr}$ ) and an output of excrement of $1.9 \pm 0.13 \mathrm{~g} / 24 \mathrm{hr}$ (dry mass). Moisture content of the excrement averaged $74.2 \pm 1.27^{\circ} .0$. None of these figures on food intake or excrement differs significantly from the corresponding value for galahs drinking water ad lib.

\section{Fluid depritation}

Five WA galahs (mean initial body mass, $278 \mathrm{~g}$ ) were prevented from drinking at $20-22 \mathrm{C}$ and $10-13$ torr humidity. They steadily lost body mass at an average rate equivalent to $2.2 \pm 0.16^{\circ}{ }_{0}$ of initial body mass per $24 \mathrm{hr}$. This does not differ significantly from the $2.5^{\circ}{ }_{o} / 24 \mathrm{hr}$ average reported for NSW galahs over 5 days of dehydration (Skadhauge \& Dawson, 1980). Food intake by four of our WA birds was measured between the fifth and eighth days of fluid deprivation. It averaged only about half the intake noted for birds consuming water ad lib. $\quad(4.3 \pm 0.97 \mathrm{~g} / 24 \mathrm{hr}$ vs $9.0 \pm 1.00 \mathrm{~g} / 24 \mathrm{hr}$ ), the difference being statistically significant $(P<0.005)$. This contrasts with the results reported for other WA galahs, which did not reduce food consumption over 3-5 days of dehydration (Skadhauge, 1974a). The food intake during fluid deprivation provided only $24.1 \mathrm{kcal} / 24 \mathrm{hr}$ (metabolizable energy). approximately $2 / 3$ the standard metabolic rate at $22 \mathrm{C}$ for normally hydrated galahs. Dry mass and percentage moisture content of the excrement voided were also lower than for birds consuming water ad lib. $(1.5 \pm 0.12 \mathrm{~g} / 24 \mathrm{hr}$ vs $1.9 \pm 0.13 \mathrm{~g} /$ $24 \mathrm{hr}, P<0.025: 67.7 \pm 0.51^{\circ}{ }_{0}$ vs $74.2 \pm 1.27^{\circ}{ }_{0}, P<$ 0.005 ). The figure of $67.7^{\circ}{ }_{n}$ moisture content of feces during water deprivation is similar to the values reported by Skadhauge \& Dawson (1980), $68.6 \pm$ $0.7^{\circ}{ }_{0}\left(3\right.$ days of dehydration) and $65.7 \pm 0.5^{\circ}{ }_{0}(5$ days of dehydration). Food intake, excrement production. and moisture content of the excrement for hydropenic galahs were also significantly lower than the corresponding figures for individuals on a minimum water ration $(P<0.01$ for difference in food intake. $<0.025$ for dry mass of excrement produced per $24 \mathrm{hr}$, and $<0.005$ for percentage moisture content).

As fluid deprivation continued. our galahs became listless, sitting quietly with their eyes closed for a substantial portion of each day. Presumably this behavior was associated with their reduced intake of food. Three birds tolerated losses of body mass amounting to $23-26^{\circ}{ }_{0}$ of initial values. The appearance of these birds at the end of the 10-day period over which these losses were incurred suggested that they were near the limit of their tolerance to the combination of water restriction and inanition. They were therefore provided with water ad lih. once again.

\section{L'se of $\mathrm{NaCl}$ solutions for drinking}

Six WA galahs were provided with $0.3 \mathrm{M} \mathrm{NaCl}$ as their sole fluid source. Two showed variable drinking rates during the first five days on this regimen. from 1.9 to 12.5 and 3.0 to $23.0 \mathrm{~g} 24 \mathrm{hr}$. In the first individual. a loss of body mass of $36.5 \mathrm{~g}$ was recorded and in the second. $31 \mathrm{~g}$. Both birds increased fluid intake after the fifth day to approximately $30 \mathrm{~g}: 24 \mathrm{hr}$ for the first and $48 \mathrm{~g} / 24 \mathrm{hr}$ for the second. The bird drinking saline at the lower rate gained $8 \mathrm{~g}$ over the next 5 days, after which body mass stabilized. This gain. which probably in part represented fluid in the gut. was not sufficient to restore body mass to the control value for the test, but it did return it to the level the bird had been maintaining in the outdoor aviary prior to being transferred indoors in preparation for the test. The bird consuming $48 \mathrm{~g}$ of saline $/ 24 \mathrm{hr}$ restored its body mass to within $0.5 \mathrm{~g}$ of the control value, over the 9 days following the initial loss. Again. this probably reflected in part fluid in the gut. This rate was the highest permitted by the capacity of the watering device and might not represent the maximal rate of consumption that this bird could attain.

Two other WA galahs used in these tests drank $0.3 \mathrm{M} \mathrm{NaCl}$ at rates that fluctuated over the test. One bird lost $41 \mathrm{~g}\left(12.6^{\circ} \%\right.$ of initial body mass) over the first 10 days, while drinking $0.3 \mathrm{M} \mathrm{NaCl}$ at rates of 6.7 to $25.1 \mathrm{~g} / 24 \mathrm{hr}$ (mean consumption. $14.4 \pm 2.05 \mathrm{~g} /$ $24 \mathrm{hr}$ ). Consumption over the next four days ranged from 16.3 to $36.0 \mathrm{~g} / 24 \mathrm{hr}$ (mean consumption. $27.7 \mathrm{~g} /$ $24 \mathrm{hr}$ ). These higher rates were accompanied by a $15-\mathrm{g}$ gain in body mass. In the other case, the galah varied its intake of saline between 4.9 and $18.4 \mathrm{~g} / 24 \mathrm{hr}$ over the 14 days of the test and this was accompanied by a $57.5 \mathrm{~g}$ loss of mass (equivalent to $18.5^{\circ}$ " of initial body mass).

One of the two remaining WA galahs consumed 3.4 and $3.3 \mathrm{~g}$ of $0.3 \mathrm{M} \mathrm{NaCl}$ solution on the first and sixth day of the test and used $1.4 \mathrm{~g} / 24 \mathrm{hr}$ or less on the other days. At the lower rates of fluid intake this bird lost body mass essentially as rapidly as galahs completely prevented from drinking.

\section{DISCUSSION}

Extent of conformance of galahs to allometric relationships

Psittaciform birds the size of the galah have received relatively little physiological study. This and the association of this cockatoo with hot and arid regions prompt a consideration of its metabolism and temperature regulation from a comparative standpoint. This is expedited by use of allometric relations for various functions established empirically with data for other birds (Table 1). The basal metabolic rate of the galah proves to be within $3^{\circ}{ }^{\circ}$ of the value anticipated for a $271 \mathrm{~g}$ nonpasserine (the mean body mass of our WA birds). Reliance on a low metabolic level thus appears not to have been a part of the adjustment of this bird to its environment. unlike the situation evident in Australian marsupials (Dawson and Hulbert. 1970) and Australian pigeons (Dawson \& Bennett. 1973). On the other hand. evaporative water loss by the galah at $25 \mathrm{C}$ is less than $2 / 3$ the anticipated value (Table 1). We initially regarded this difference with some skepticism. for the allometric relation involved in the comparison is based on more limited data than that for metabolism. Moreover, many of the measurements of evaporative water loss were obtained while the birds, unlike the galah, were in the active phase of their daily cycle. However, the galah 's rate also proves to be low in direct comparisons with two birds of comparable size studied by Calder \& 
Table 1. Observed and predicted values for physiological functions of the galah*

\begin{tabular}{|c|c|c|c|c|c|c|}
\hline \multirow[b]{3}{*}{ Function } & \multicolumn{2}{|c|}{ Values } & & & & \\
\hline & (a) & (b) & & & Equationt & \\
\hline & Obs. & Pred. & $a / b$ & & for $b$ & Reference \\
\hline BMR $\dot{V} \mathrm{O}_{2 \mathrm{~h}}\left(\mathrm{~cm}^{3} \mathrm{O}_{2} \cdot \mathrm{g}^{-1} \cdot \mathrm{hr}^{-1}\right)$ & 0.93 & 0.90 & 1.03 & (1) & $\dot{V} \mathrm{O}_{2 b}=4.01 \mathrm{~m}^{-0266}$ & Aschoff \& Pohl (1970) \\
\hline $\mathrm{EWL}$ at $25 \mathrm{C}, \dot{\mathrm{m}}_{\mathrm{we}}\left(\mathrm{mg} \cdot \mathrm{g}^{-1} \cdot \mathrm{hr}^{-1}\right)$ & 0.92 & 1.76 & 0.52 & (2) & $\dot{m}_{\mathrm{wc}}=18.0 \mathrm{~m}^{-0.415}$ & $\begin{array}{c}\text { Crawford \& Lasiewski } \\
\qquad(1968)\end{array}$ \\
\hline$E W L_{\text {mux }}, \dot{m}_{\mathrm{we}}^{m m^{2 x}}\left(\mathrm{mg} \cdot \mathrm{g}^{-1} \cdot \mathrm{hr}^{-1}\right)$ & 22.3 & 20.2 & 1.10 & (3) & $\dot{m}_{\mathrm{wc}}^{\mathrm{max}}=61.8 \mathrm{~m}^{-020}$ & Calder \& King (1974) \\
\hline$h_{\min }\left(\mathrm{cal} \cdot \mathrm{g}^{1} \cdot \mathrm{hr}^{-1} \cdot \mathrm{C}^{-1}\right)$ & $0.193 \dagger$ & 0.180 & 1.07 & (4) & $h_{\min }=4.06 \mathrm{~m}^{-0.54}$ & Calder \& King (1974) \\
\hline \multirow[t]{2}{*}{$T_{\mathrm{s}}(\mathrm{C})$} & 17.0 & 22.0 & 0.77 & $(5)$ & $T_{\mathrm{n}}^{\min }=4.73 \mathrm{~m}^{0.2-4}$ & Calder \& King (1974) \\
\hline & 21.8 & 23.0 & 1.00 & & & \\
\hline$h_{\mathrm{d}}^{\mathrm{max}}\left(\mathrm{cal} \cdot \mathrm{g}^{-1} \cdot \mathrm{hr}^{-1} \cdot \mathrm{C}^{-1}\right)$ & 1.111 & 0.499 & 2.23 & $(6)$ & $h_{d}^{m-1 x}=15.31 m^{-0.611} s$ & Calder \& King (1974) \\
\hline
\end{tabular}

\footnotetext{
* Unless otherwise indicated, values pertan to 271 -g birds. The observed values were obtained in summer for WA galahs (see text).

$+m$ is body mass in $g$.

$\mp$ Value pertains to $321-\mathrm{g}$ birds. The observed values were obtained or calculated for NSW individuals in winter

Based on observations for $T_{\mathrm{l}}$ between 43.8 and $46.5 \mathrm{C}$.
}

Schmidt-Nielsen (1967). At 27.1 C, the galah's rate is only $55^{\circ}{ }_{0}$ the nocturnal value for the $285-\mathrm{g}$ greater roadrunner (Geococcyx californianus). a ground cuckoo inhabiting North American deserts. At $31.5 \mathrm{C}$ it is $59^{\circ}$; the nocturnal value reported for the $315-\mathrm{g}$ domestic pigeon (Columba livia). Such a relatively low rate appears quite adaptive to an environment in which foraging activities may carry galahs away from surface water for hours and, perhaps, days.

Table 1 reveals further that the relatively low rates of evaporation by galahs at moderate temperatures are not linked with restricted powers of heat defense. The rates of evaporative water loss noted in our tests at $47-48 \mathrm{C}$, the highest $T_{4}$ at which the birds did not become overheated, average $22.3 \mathrm{mg}(\mathrm{g} \cdot \mathrm{hr})^{-1}, 111^{\circ}{ }_{\mathrm{o}}$ of the rate predicted for a $271 \mathrm{-g}$ nonpasserine.

Allometric relations established for birds also permit consideration of some coetficients pertaining to insulative capacities of the galah (Table 1). We have based our consideration of the minimal value of the heat transfer coefficient $h$ (quotient of heat production divided by difference between $T_{\mathrm{b}}$ or $T_{\mathrm{c}}$ and $T_{\mathrm{s}}$ ) on results obtained for the four NSW galahs during winter (mean body mass. $321 \mathrm{~g}$ ). The mean value of $h_{\min }$ for these birds at subfreezing $T_{a}$ $\left(0.193 \mathrm{cal} \cdot \mathrm{g}^{-1} \cdot \mathrm{hr}^{-1} \cdot \mathrm{C}^{-1}\right)$, exceeds that predicted for a $321 \mathrm{-g}$ bird by only $7^{\circ}{ }_{0}$. If the metabolism-temperature relation for NSW galahs in winter conforms to the model presented by Scholander et al. (1950). the minimal values for $h$ would yield a value of $21.8^{-}$for $T_{S_{2},}$ the critical thermal gradient, which is the difference between $T_{\mathrm{b}}$ and the lower critical temperature, $T_{\mathrm{lc}}\left(T_{\mathrm{sc}}\right.$ is the quotient of $\dot{H}_{\mathrm{b}} / h_{\min }$, where $\dot{H}_{\mathrm{b}}$ is basal heat production, the product of 4.8 times the $\dot{V} \mathrm{O}_{2 \mathrm{~b}}$ predicted for a $321 \mathrm{-g}$ bird with equation 1 from Table 1 , and $h_{\mathrm{m} \text { I }}$ is $\left.0.19 \mathrm{cal} \cdot \mathrm{g}^{-1} \cdot \mathrm{hr}^{-1}, \mathrm{C}^{-1}\right)$. The value of $21.7 \mathrm{C}$ for $T_{s c}$ is slightly smaller than that of $23.0 \mathrm{C}$ obtained from equation 5 in Table 1 . For a $T_{b}$ of $39.5 \mathrm{C}$ (Fig. 2) these values yield $T_{\mathrm{lc}}$ of 17.8 and $16.5^{-} \mathrm{C}$, respectively. Less satisfactory agreement exists between observed and predicted values of $T_{\Delta c}$ of WA galahs in summer. Inspection of Fig. 4 suggests that the lower critical temperature for these birds in summer is near $22.5 \mathrm{C}$, indicating a $T_{\mathrm{Ac}}$ of $17.0 \mathrm{C}$ for a $T_{\mathrm{b}}$ of $39.5 \mathrm{C}$. However the value predicted for a $271 \mathrm{Ig}$ bird using equation 5 in Table 1 is $22.0 \mathrm{C}$. Perhaps these results coupled with those on NSW galahs in winter indicate a seasonal change in insulation. Unfortunately, the possibility that the WA birds were not tested at $T_{d}$ low enough to evoke minimal values of $h$ cannot be excluded.

A final function treated in the comparisons in Table 1 is for the dry heat transfer coefficient (the quotient of heat production less evaporative heat loss divided by the difference between $T_{\mathrm{b}}$ and $T_{\mathrm{a}}$ ) for $T_{\mathrm{d}}$ exceeding $T_{\mathrm{b}}$. The mean value of $h_{\mathrm{d}}^{\max }$ for the WA galah in summer is more than twice that predicted with equation 6 from Table 1 . In this case, the figures for the galah and greater roadrunner $\left(1.11\right.$ and $1.02 \mathrm{cal} \cdot \mathrm{g}^{-1} \cdot \mathrm{hr}^{-1}$. ${ }^{\circ} \mathrm{C}^{-1}$, respectively) agree within $10^{\circ}{ }_{0}$. The galah. like the majority of birds tested thus far, show relatively high $h_{\mathrm{d}}^{\max }$ at $T_{\mathrm{a}}$ above $T_{\mathrm{b}}$. The increased heat flow into the bird from the environment fostered by this enhances the need for evaporative cooling, with attendant deleterious effect on the water economy of the bird (see Dawson \& Fisher, 1969; Calder \& King, 1974).

\section{Heat defense}

Galahs greatly increased $\dot{m}_{w c}$ in hot environments (Fig. 5). Panting was a conspicuous element in this response, its action apparently being enhanced by a form of gular flutter associated with movements of the fleshy tongue. The apparent coincidence of these movements with breathing activity is an arrangement shared with representatives of the avian families Phasianidae (quail). Cuculidae (cuckoos). Columbidae (doves and pigeons). Tytonidae (owls), and Strigidae (owls) (Lasiewski, 1972). Unfortunately, we lacked equipment to ascertain the extent of dependence of panting and flutter frequency on heat load.

Conversion of the data on metabolism and evaporative water loss to thermal units allows assessment of the contribution of evaporative cooling to the thermal regulation of galahs (Fig. 6). This mode of heat dissipation accounts for approximately $1 / 10$ of heat production between 21 and $33 \mathrm{C}$. The proportion increases rapidly with $T_{1}$ above $33 \mathrm{C}$. reaching $\mathrm{I} .0$ just above $41^{\prime} \mathrm{C}$, within $1^{-} \mathrm{C}$ of the level at which $T_{\mathrm{h}}$ equals $T_{4}$. Above $45 \mathrm{C}$, heat loss through evaporation exceeds that produced in metabolism by $1.4-1.7 \times$. These factors compare favorably with those noted for 


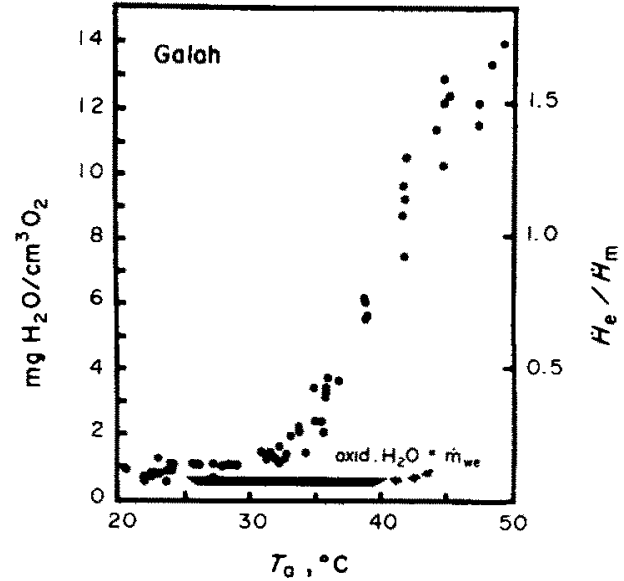

Fig. 6. Ratios of evaporative water loss to oxygen consumption, $\dot{m}_{w e} / \dot{V O}$, (based on data from Figs 4 and 5 and expressed as $\mathrm{mg} \mathrm{H}_{2} \mathrm{O}$ evaporated per $\mathrm{cm}^{3} \mathrm{O}_{2}$ consumed) at various ambient temperatures $\left(T_{4}\right)$. The upper border of the horizontal bar marks the approximate maximal ratio $\left(0.6 \mathrm{mg} \mathrm{H} \mathrm{H}_{2} \mathrm{O} / \mathrm{cm}^{3} \mathrm{O}_{2}\right)$ at which oxidative production of water could offset $\dot{m}_{w e}$ for a seed-eating bird such as a galah. Corresponding values of $\dot{m}_{w e}$ and $\dot{V} \mathrm{O}_{2}$ were converted to thermal terms using caloric equivalents of $0.58 \mathrm{cal} / \mathrm{mg} \mathrm{H}_{2} \mathrm{O}$ and $4.8 \mathrm{cal} / \mathrm{cm}^{3} \mathrm{O}_{2}$. respectively. These have been used to determine the proportion of metabolic heat production $\dot{H}_{\mathrm{m}}$ dissipated by evaporative heat loss. $\dot{H}_{\text {. }}$ (see righthand ordinate) at various $T_{\Delta}$

other birds having metabolic levels similar to those anticipated from allometric relationships (see Table 1 and Dawson \& Hudson, 1970; Calder \& King, 1974). They are similar to the maximum ratios reported for two other psittaciform birds, monk parakeets (Myiopsitta monachus) and budgerygahs (Melopsittacus undulatus) (Weathers \& Caccamise, 1975; Weathers \& Schoenbaechler, 1976).

Enhancement of evaporative cooling is but one component of the response of galahs to heat. These birds share in a general avian tendency toward hyperthermia in hot environments (Figs 2 and 3). This appears to be a carefully regulated condition that places these birds in a more favorable position regarding heat exchange (see Dawson \& Hudson. 1970: Calder \& King, 1974). The fact that this reduces demands for evaporative cooling must be of value in reconciling the antagonistic requirements for maintaining thermal and water balance in an arid environment.

\section{Water budgets}

Water budgets have been constructed for WA galahs under three regimens at $20-22 \mathrm{C}$ (Table 2 ). That for birds drinking water ad lib. involves acquisition of $18.2 \mathrm{~g} \mathrm{H}_{2} \mathrm{O} / 24 \mathrm{hr}$. At metabolic levels 1.2 and $14 \times$ SMR, evaporative water loss is estimated at 6.4 and $7.5 \mathrm{~g}_{/} 24 \mathrm{hr}$. respectively. Cloacal water loss is calculated at $6.7 \mathrm{~g}_{i} 24 \mathrm{hr}$, leaving an excess of $5.0 \mathrm{~g} 24 \mathrm{hr}$. Our estimate of the percentage of water in excrement. which is based on only a portion of the material voided in tests. may be in error. The budget for birds drinking $a d$ lit. can be balanced if the mean moisture content of the excrement is taken as $84^{\circ}{ }_{0}$ rather than

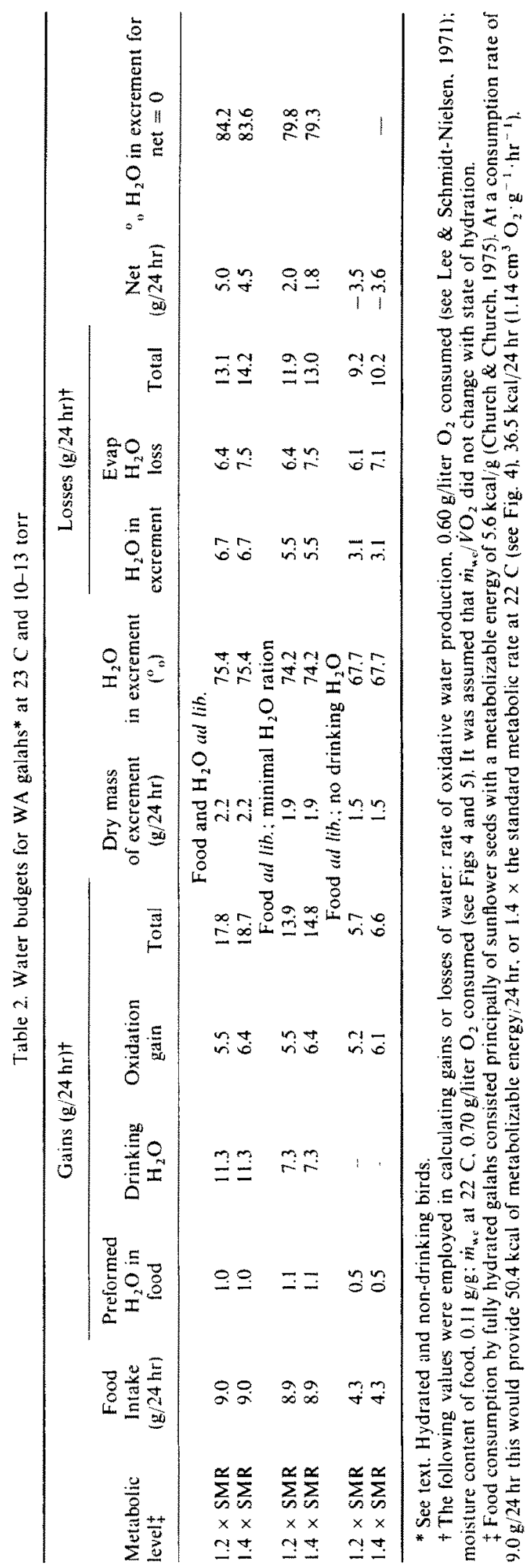


$75^{\circ}$. (Table 2). The higher figure seems well within the range of avian capacities generally (Dawson \& Bartholomew. 1968: Dawson et al.. 1979) and of the galah in particular, which Skadhauge \& Dawson (1980) found to void excrement having a moisture content of $82.5^{\circ}$, (associated with a cloacal water loss of $5.6 \mathrm{~g} / 24 \mathrm{hr}$ ) when water was available ad lib. The discrepancy between estimates of water acquisition and loss by galahs could also reflect the birds' spilling fluid from their water dishes during tests, although precautions were taken to exclude results where this might have been a factor. If spillage did occur, the $75^{\circ}$ figure for moisture content of the excrement might well suffice for helping balance acquisition and loss. It is of interest that Cade \& Dybas (1962) found the moisture content of the excrement voided by another xerophilic psittacine, the budgerygah, to average $75-80^{\circ}$.

Above $20^{\circ} \mathrm{C}$ evaporative water loss by galahs outstrips production of water through oxidation (Fig. 6) and this should lead to a dependence on drinking unless the birds make extensive use of succulent food. The minimal ration of drinking water on which our WA galahs were observed to maintain body mass while subsisting on seeds in tests at $20-22^{\circ} \mathrm{C}$ approximated $7.3 \mathrm{~g} / 24 \mathrm{hr}$. This is $59^{\circ}{ }_{\circ}$ of the ad lib. rate of drinking by these birds at $20-22 \mathrm{C}$. The corresponding figures for 11 other taxa of birds that must drink to subsist on a seed diet range from 28 to $85^{\circ}$. and average $56^{\circ}$, based on data listed in Dawson \& Bartholomew (1968). The ratio for the galah is closest to those obtained for the Inca dove. Scardafella inca (MacMillen \& Trost, 1966) and house finch. Carpodacus mexicanus (Bartholomew \& Cade. 1956), 56 and $63^{\circ}{ }^{\circ}$, respectively. Total water acquisition by galahs drinking at the rate of $7.3 \mathrm{~g} / 24 \mathrm{hr}$ is estimated at 13.4 and $14.3 \mathrm{~g} / 24 \mathrm{hr}$ for metabolic rates 1.2 and $1.4 \times$ SMR. respectively (Table 2). Evaporative water losses are calculated at 6.4 and $7.5 \mathrm{~g} / 24 \mathrm{hr}$, for these metabolic levels and cloacal water loss is placed at $5.5 \mathrm{~g} / 24 \mathrm{hr}$. This leaves surpluses of 1.5 and $1.3 \mathrm{~g} / 24 \mathrm{hr}$ for metabolic levels 1.2 and $1.4 \times$ SMR, respectively. As noted above, a possible source of the discrepancy could be an underestimation of the average moisture content of the excrement. Were this approximately $78^{\circ}$, instead of $74^{\circ}{ }_{0}$ (Table 2), the budget would come into balance. As mentioned previously, Skadhauge \& Dawson (1980) report an average moisture content of $82.5^{\circ}$ for the excrement of hydrated galahs.

The daily water losses of WA galahs on $a d \mathrm{lib}$, and minimal water rations are approximately 18 and $14 \mathrm{~g} / 24 \mathrm{hr}$. respectively (Table 2 ), as noted previously. These values are well below those reported for greater roadrunners of similar size, ca. $290 \mathrm{~g}$ (Ohmart et al. 1970), which averaged $42 \mathrm{~g} / 24 \mathrm{hr}$ (birds provided water $a d l i b$. and succulent diet) and $26 \mathrm{~g} / 24 \mathrm{hr}$ (birds deprived of drinking water but provided with succulent diet). Differences in conditions in tests involving the two species (e.g. in $T_{\lrcorner}$. atmospheric humidity, photoperiod, and moisture content of the diet) probably account for part of this disagreement. However, the tendency of galahs to lose less water in the absence of heat stress than roadrunners is probably also involved (see above).

Captive galahs which we prevented from drinking for 5-8 days showed reduced food intake and activity.
The former contributed to lower cloacal water loss by reducing excrement production, as $\mathrm{McF}$ arland \& Wright (1969) noted for the Barbary dove (Streptopelia risoria). Curtailment of activity should assist in lowering the loss of water through evaporation. Daily acquisition of oxidation water by hydropenic galahs would amount to 5.7 and $5.2 \mathrm{~g}$ at 1.4 and $1.2 \times$ SMR. respectively. The corresponding watcr deficits would be 3.5 and $3.1 \mathrm{~g} / 24 \mathrm{hr}$ (Table 2). These deficits are linked with an estimated rate of $3.2 \mathrm{~g} / 24 \mathrm{hr}$ for cloacal water loss (Table 2). Skadhauge's (1974a) direct measurement of cloacal water excretion by WA galahs on the third day of not drinking yields substantially lower values: 101 and $124 \mu \mathrm{l}(\mathrm{kg} \cdot \mathrm{hr})^{-1}$. which correspond to total daily losses of 0.7 and $0.8 \mathrm{~g}$ $\mathrm{H}_{2} \mathrm{O} / 24 \mathrm{hr}$. At the mean rate of dry excrement production in our tests $(1.5 \mathrm{~g} / 24 \mathrm{hr})$, this would require the voiding of material averaging $31-35^{\circ}{ }_{0}$ in moisture content, figures well below the means for most birds that have been observed under water restriction (Dawson \& Bartholomew, 1968: Bartholomew, 1972). However, individuals of some of these species can reduce the moisture content of their excrement to approximately $30^{\circ}{ }_{0}$ (Smyth \& Bartholomew, 1966; Willoughby. 1968; Dawson et al, 1979). Even if Skadhauge's estimates of total water excretion are applicable to the present case. the galahs would still be in negative water balance by 0.6 to $0.7 \mathrm{~g} / 24 \mathrm{hr}$ or by 1.0 to $1.1 \mathrm{~g} / 24 \mathrm{hr}$ at $1.2 \times$ or $1.4 \times \mathrm{SMR}$, respectively. Whether one accepts rates of cloacal water loss of $0.6-1.1 \mathrm{~g} / 24 \mathrm{hr}$ or $3.1-3.5 \mathrm{~g} / 24 \mathrm{hr}$, the water deficits incurred by birds prevented from drinking are substantially below the rate at which their body mass declines $(\mathrm{ca} 6 \mathrm{~g} / 24 \mathrm{hr}$ ). Such a condition is consistent with the birds' being in negative energy balance as well as negative water balance. It is of interest in attempting to reconcile the various observations on water economies of galahs to note that Skadhauge \& Dawson (1980) report a substantially higher value for cloacal water loss in NSW galahs on the third day of dehydration than the figure obtained by Skadhauge (1974a) for WA birds, $2.9 \mathrm{~g} / 24 \mathrm{hr}$ vs $0.7-0.8 \mathrm{gi}$ $24 \mathrm{hr}$. The former figure is close to that we obtained (Table 2).

\section{Use of $\mathrm{NaCl}$ solutions}

Galahs under water restriction can produce ureteral urine up to 2.5 times as concentrated osmotically as their plasma. 982 vs $400 \mathrm{~m}$-Osmoles/l /Skadhauge, 1974a). Moreover, the functional properties of their coprodeum and posterior large intestine are such that this hyperosmotic urine can pass into the cloaca without fostering any osmotic loss of water from the adjacent tissues (Skadhauge. 1974b). These capacities, coupled with the contributions of uricotelism to electrolyte excretion (McNabb \& McNabb. 1975), should provide galahs with some abilities to utilize saline waters for drinking. This is verified by the performance of some individuals in tests where the only source of fluid for drinking was $0.3 \mathrm{M} \mathrm{NaCl}$. These birds were able to reverse the downward trend in their body mass once they began drinking appreciable quantities of this solution. In their ability to benefit from use of $0.3 \mathrm{M} \mathrm{NaCl}$, these individuals compare favorably with a number of other birds that have been tested (see Table III in Dawson \& Bartho- 
lomew, 1968). However, other galahs either ingested so little $0.3 \mathrm{M} \mathrm{NaCl}$ or failed to drink at all that they continued to decline. This individual variation in readiness to use $\mathrm{NaCl}$ solutions is reminiscent of the situation described for budgerygahs (Greenwald et al.. 1967). Taste or related factors appear in some instances to outweigh any benefits to water balance that use of saline solutions can provide. This also seems to apply in nature; Fisher et al. (1972) describe how a relatively dilute pool on the Murchison River, Western Australia, was not used by birds including galahs. possibly as a result of its containing $24 \mathrm{mmoles} / \mathrm{l}$ of magnesium.

\section{Water balance in nature}

The analysis of water budgets for galahs indicates a requirement for preformed water, even at moderate temperatures. In some instances this may be obtained through ingestion of succulent food rather than by drinking, judging by the limited use of surface water characterizing these birds during winter (Fisher et al., 1972). The increase in expenditure of water in evaporative cooling during hot weather leads to a dependence on surface water and galahs are regularly observed drinking at watering points in the interior of Australia during summer (Fisher et al., 1972). They must divide their time between visiting such points and reaching areas where food is available, some of which may be distant from surface water. They are aided in this by an ability to tolerate rises in plasma osmolality and plasma sodium concentration of at least 19 and $11^{\circ}{ }_{0}$, respectively (Skadhauge, 1974a). The galah resembles the western mourning dove (Zenaidura macroura marginella) in its mode of existence (Dawson \& Bartholomew. 1968). the two birds' drinking regularly. but undergoing dehydration in between times. The fact that birds collected by Skadhauge (1974a) were not concentrating urine to maximum levels suggests that they do not ordinarily utilize anything approaching their full defense against hydropenia.

The tendency of our experimental birds to reduce activity and food intake when prevented from drinking probably reflects the lack of other options in captivity. In the week or two that galahs seem able to go without drinking, free living individuals should fare better in the face of a local unavailability of surface water if they undertook movements allowing them to reach new and possibly distant sources of water.

Given their reliance on surface water. it is quite possible that galahs have benefited from the introduction of pastoralism into Australia since the advent of Europeans. The requirements of stock for water have led to the widespread introduction of bores and dams that have greatly increased the supply of surface water available. Galahs are among the most conspicuous users of these artificial watering points (Fisher et al.. 1972: Davies. 1972. 1977).

Acknowledgements - This investigation was supported in part by grants to W.R.D. from the National Science Foundation (GB-3656. DEB 77-25487. DEB 80-21389) and the Horace H. Rackham School of Graduate Studies. The University of Michigan. We are grateful to Professors A. R. Mam and the late $H$. Warng for numerous courtesies and use of the facilities of The Department of Zoology. University of Western Australia. Nedlands. We also wish to thank
Professor T. J. Dawson for similar support in The School of Zoology, University of New South Wales. Kensington.

\section{REFERENCES}

Aschoff J. \& PoHL H. (1970) Rhythmic variations in energy metabolism. Fedn Proc. Fedn Am. Socs exp. Biol. 29, 1541-1552.

BARTHOLOMEW G. A. (1972) The water economy of seedeating birds that survive without drinking. Proc. $X V t h$ int. ornith. Congr., 237-254.

Bartholomew G. A. \& CADE T. J. (1956) Water consumption of house finches. Condor 58, 406-412.

Cade T. J. \& Drbas JR. J. A. (1962) Water economy of the budgerygah. Auk 79, 345-364

Calder W. A. \& King J. R. (1974) Thermal and caloric relations of birds. In Acian Biology. Vol. IV (Edited by FarNeR D. S. \& KING J. R.) pp. 259-413. Academic Press. New York.

Calder W. A. \& Schmidt-Nielsen K. (1967) Temperature regulation and evaporation in the pigeon and the roadrunner. Am. J. Physiol. 213, 883-889.

Church C. F. \& Church H. N. (1975) Food Values of Portions Commonly Used. 12th edn. J. P. Lippincott. Philadelphia.

Crawford E. C.. JR \& Lasiewski R. C. (1968) Oxygen consumption and respiratory evaporation of the emu and rhea. Condor 70, 3j3-339.

Davies S. J. J. F. (1972) Results of 40 hours continuous watch at five water points in an Australian desert. Emu 72, 8-12.

DAviEs S. J. J. F. (1977) Man's activities and birds' distribution in the arid zone. Emu 77, 169-172.

Dawson T. J. \& Hulber A. J. (1970) Standard metabolism. body temperature. and surface areas of Australian marsupials. Am. J. Physiol. 218, 1233-1238.

Dawson W. R. \& Bartholomew G. A. (1968) Temperature regulation and water economy of desert birds. In Desert Biology; Vol. 1 (Edited by BRown JR G. W.I pp. 357-394. Academic Press. New York.

DAwson W. R. \& BENNETt A. F. (1973) Roles of metabolic level and temperature regulation in the adjustment of western plumed pigeons (Lophophaps ferruginea) to desert conditions. Comp. Biochem. Physiol 44A, 249--266. Dawson W. R. Carey C. Adkisson C. S. \& Ohmart R. D. (1979) Responses of Brewer's and chipping sparrows to water restriction. Physiol Zool. 52, 529-541.

Dawson W. R. \& Fisher C. D. (1969) Responses to temperature by the spotted nightjar (Eurostopodus guttatus). Condor 71, 49-53.

Dawson W. R. \& Hudson J. W. (1970) Birds. In Comparative Physiology of Thermoregulation. Vol. 1 (Edited by Whitrow G. C.) pp. 223-310. Academic Press. New York

Fisher C. D., Lindgren E. \& Dawson W. R. (1972) Drinking patterns and behavior of Australian desert birds in relation to their ecology and abundance Condor 74, $111-136$.

Greenwald L.. Stone W. B. \& Cade T. J. (1967) Physiological responses of the budgerygar (Melopsittucus undulatus) to dehydrating conditions. Comp. Biochem. Physiol. 22, $91-100$.

Johnson O. W. \& Skadhauge E. (1975) Structural-functional correlations in the kidneys and observations of colon and cloacal morphology in certain Australian birds. J. Anat. 120, 495-505.

LASIEWSKI R. C. (1972) Respiratory function in birds. In Atian Biology, Vol. II (Edited by FARNER D. S. \& King J. R.) pp. 287-342. Academic Press, New York.

LeE P. \& SChmidt-NielSeN K. (1971) Respiratory and cutaneous evaporation in the zebra finch: effect on water balance. Am. J. Phisiol. 220, 1598-1605. 
MCFarland D. \& Wright P. (1969) Water conservation by inhibition of food intake. Physiol. Behav. 4, 95-99.

Macmillen R. E. \& Trost C. H. (1966) Water economy and salt balance in white-winged and Inca doves. Auk 83, $441-456$.

MCNaBB R. A. \& MCNABB F. M. A. (1975) Urate excretion by the avian kidney. Comp. Biochem. Physiol. 51A, 253-258.

Ohmart R. D. Chapman T. E. \& McFarland L. Z. (1970) Water turnover in roadrunners under different environmental conditions. Auk 87, 787-793.

SCholander P. F.. HOCK R., Walters V., Johnson F. \& IRVING L. (1950) Heat regulation in some arctic and tropical mammals and birds. Biol. Bull. 99, 237-258.

SKADHAUGE E. (1974a) Renal concentrating abilities of selected West Australian birds. J. exp. Biol. 61, 269276.

Skadhauge E. (1974b) Cloacal resorption of salt and water in the galah (Cacatua roseicapilla). J. Physiol. (London) 240, 763773 .

Skadhuage E. \& Dawson T. J. (1980) Excretion of several ions and water in a xerophilic parrot. Comp. Biochem. Phisiol. 65A, 325-330.

SMYTH M. \& BarTholomew G. A. (1966) The water economy of the black-throated sparrow and the rock wren. Condor 68, 447-458.

Weathers W. W. \& CaCCamise D. F. (1975) Temperature regulation and water requirements of the monk parakeet. Myiopsitta monarchus. Oecologia (Berlin) 18, $329-42$.

Weathers W. W. \& Schoenbaechler D. C. (1976) Regulation of body temperature in the budgerygah, Melopsittacus undulatus. Aust. J. Zool. 24. 39-47.

WilloughBy E. J. (1968) Evaporative water loss of a small xerophilous finch Lonchura malabarica. Comp. Biochem. Physiol. 28, 655-664. 